\title{
Reaction Time of a Group of Physics Students
}

\author{
Charu Saxena, Rini Kaur \& P.Arun \\ Department of Physics and Electronics, \\ S.G.T.B. Khalsa College \\ University of Delhi, Delhi 110 007, India.
}

October 27, 2018

\begin{abstract}
The reaction time of a group of students majoring in Physics is reported here. Strong co-relation between fatigue, reaction time and performance have been seen and may be useful for academicians and administrators responsible of working out time-tables, course structures, students counsellings etc.
\end{abstract}

\section{Introduction}

Animal's respond to the environment using their sensory organs for collecting information that is passed on to the brain and analyzed for action. However, this would take a perceivable time. This time is called the reaction time. The definition of reaction time or latency as given in the wikipedia is "the time from the onset of a stimulus until the organism responds" [1]. Human reaction time is ultimately limited by how fast nerve cells conduct nerve impulses. Although this speed is almost 250 miles per hour, messages still take a significant amount 
of time to travel from sensory organs to the brain and back to the appropriate muscle groups.

A common "experiment" done as a game by children is for one boy to hold a scale about chest high and have someone place his thumb and index finger about an inch apart somewhere along the (bottom) length of the scale. Now, he would have to catch the scale when the first boy allows it to fall. The scale won't be able be caught immediately and a length of the scale would pass through his finger before it is caught. From simple laws of mechanics, using the equation

$$
t=\sqrt{\frac{2 s}{g}}
$$

the reaction time of the child can be calculated. Interest in the measurement of human reaction time apparently began as a result of the work of a Dutch physiologist named F.C.Donders. Beginning in 1865, Donders [2] became interested in the question of whether the time taken to perform basic mental processes could be measured. Until that time, mental processes had been thought to be too fast to be measurable. In his early experiments, Donders applied electric shocks to the right and left feet of his subjects. The subject's task was to respond by pressing a telegraph key with his right or left hand to indicate whether his right or left foot had received the shock. Interest in measuring and minimizing the reaction time today is of interest in medicine, military, traffic control and sports. Things can be put to better perspective by taking an example. In the game of cricket, the average distance between the bowler and batsman is $20 \mathrm{mtrs}$. With a spin bowler delivering the ball at around $80 \mathrm{Km} / \mathrm{hr}$, the batsman has $0.9 \mathrm{~s}$ (900ms) to "see" the ball, decide the shot and implement it! An analysis of high-speed film of international cricketers batting on a specially prepared pitch which produced unpredictable movement of the ball is reported, and it is shown that, when batting, highly skilled professional cricketers show reaction times of 


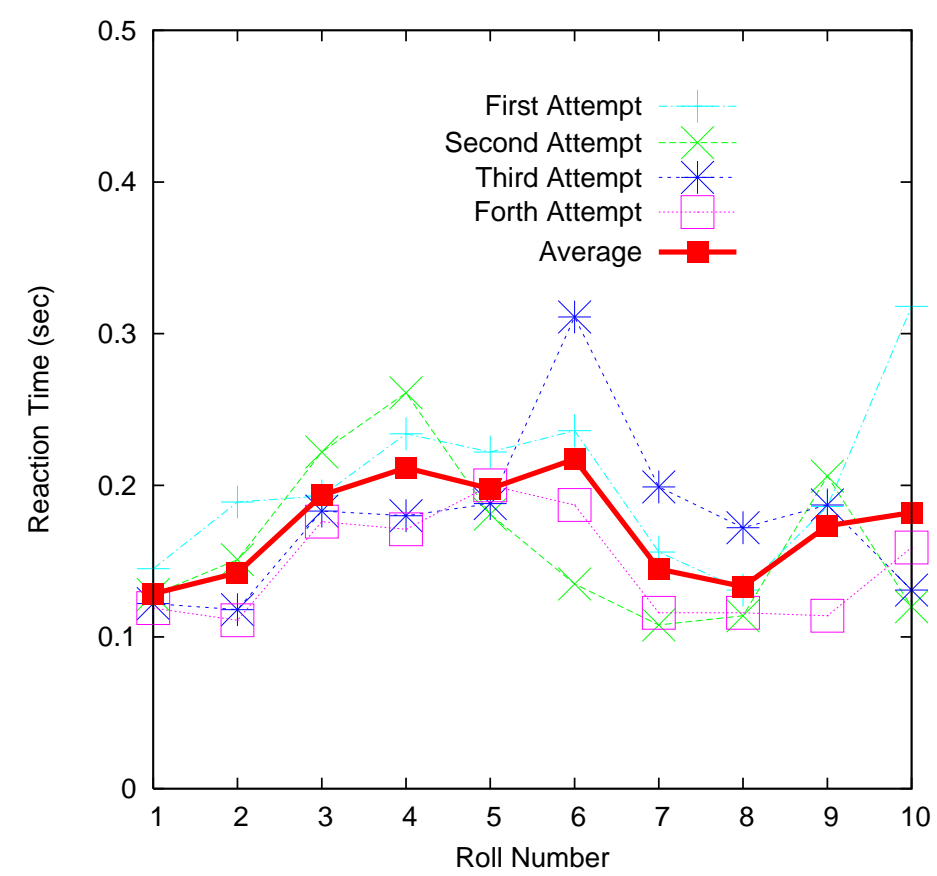

Figure 1: The dark thick line shows the variation of the average time recorded by the students of the given roll number. The repeated attempts of the students resulted in an average $\pm 0.422 \mathrm{~s}$ deviation from the their average.

around $200 \mathrm{~ms}[3]$.

Various methods have been used to measure the reaction time. Essentially, measuring simple reaction time like in Donders experiment or recognition reaction time or choice reaction time. In choice reaction time experiments the subject must give a response that corresponds to the stimulus, such as pressing a key corresponding to a letter as soon as the letter appears on a display amist random display of characters. In this article we are reporting the results of our experiment done using this method. The reaction time is known to be effected by factors such as age, gender, fatigue/ exercise, distractions and intelligence. Our sample group were students of physics/ electronics in the age group of 1821 , where studies have shown the reaction time to be the minimum in a human 
life span [4, 5, 6, 17, 8]. These works report the reaction time of people in the age group of our study to be $\sim 200 \mathrm{~ms}$.

\section{Results}

We have sampled and recorded the reaction time of 137 students, however, here we discuss data of 44 students who were majoring in physics/ electronics. Usually such experiments sample 20 or more people and make them repeat the experiment over large time [9. Another approach is where single reading is taken after allowing the test person a period of practice [10. We first tested the effect of practice on a group of students. Fig 1 shows a the variation of reaction time of students with increasing practice. Raw reaction time, i.e. the first attempt, of the students were poor. As they practiced, a recording was taken at every 15 minutes. Practice however did not keep on improving the reaction time. Only four out of ten students had better reaction time on their forth recording (i.e. after 45 minutes of practice) as compared to their third try (30 minutes into practice). While one might be tempted to conclude this as improvement with practice, it should be noted that three of these four students in their forth attempt performed worse then their second attempt. The spectrum of reaction time is within $\pm 0.422 \mathrm{~s}$ of the average values. This deviation is just $\pm 0.075 \mathrm{~s}$ when the first attempt is neglected. Hence, in our experiment, our approach has been to allow a subject to familiarize the machine for 20-25 minutes before taking their reaction time.

Fig 2 shows the performance of the students from the first, second and third years majoring in Physics/ Electronics. Along with each histogram, a Gaussian

$$
f(x)=a e^{-\frac{(x-b)^{2}}{2 c^{2}}}
$$


was fitted to estimate the mean reaction time (b) of the class and the deviation from the mean (using c). Table 1 details the results for all three classes. The
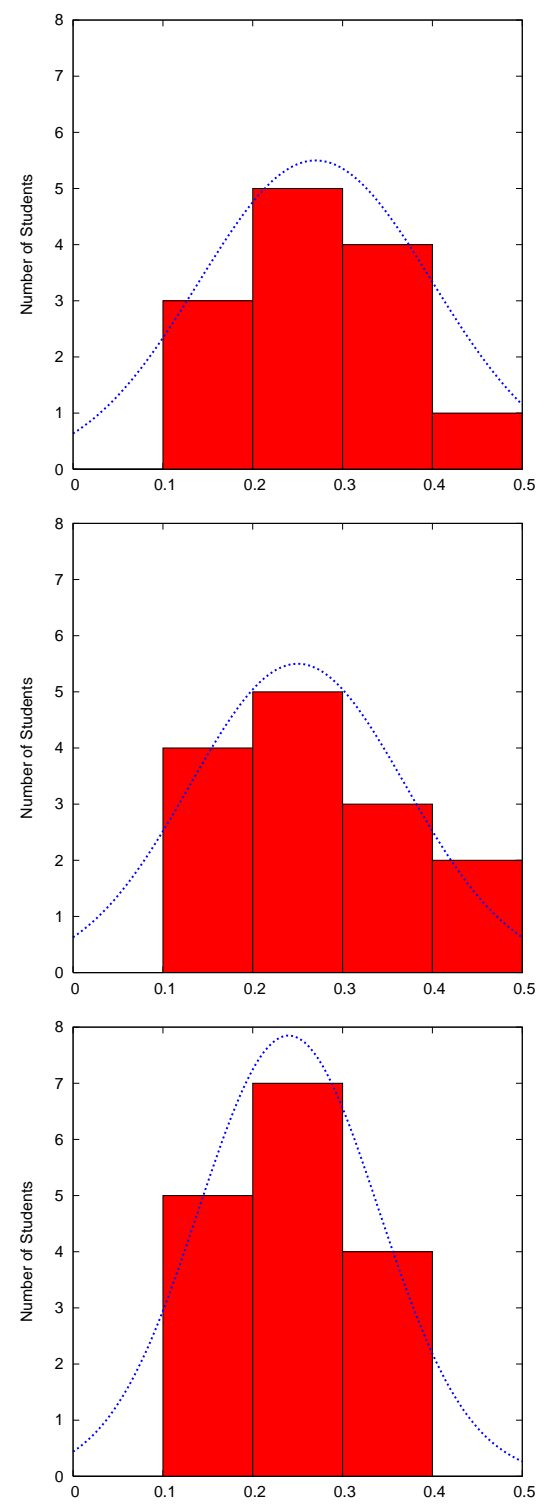

Figure 2: The distribution of the reaction time of the $1^{\text {st }}$ year, $2^{\text {nd }}$ year and $3^{\text {rd }}$ year majoring in physics/ electronics. 
Table 1: Table compares the male-female distribution of the three classes and their preformances.

\begin{tabular}{|c|c|c|c|c|}
\hline Class & Girls & Boys & $\mathrm{c}$ & Marks Obtained \\
\hline $1^{\text {st }} \mathrm{y}$ & 6 & 8 & 0.13 & 69 \\
\hline $2^{\text {nd }} \mathrm{y}$ & 4 & 14 & 0.12 & 74 \\
\hline $3^{\text {rd }} \mathrm{y}$ & 9 & 5 & 0.10 & 87 \\
\hline
\end{tabular}

lower mean reaction time and narrower deviation from the mean of the third year students show a collective better performance. A boarder sampling of reaction time with larger age variation was collected based on gender (results not shown here). We found no variation in performance based on gender with the ratio of female to male reaction time being equal to unity, i.e. $\left(R_{F M}=1\right)$. Bellis [11] and Engel 12 reported $R_{F M}=1.1$, with males having a faster reaction time. However, recent studies by Silverman [13] reports the difference in male-female reaction time was narrowing. Table 1 gives the number boys and girls in each class. Eventhough ratio of boys and girls are not same in these classes, no correction is called for in fig 3 since $\mathrm{R}_{\mathrm{FM}}=1$.

As stated earlier, the $3^{\text {rd }}$ year students appear to be a sharper lot and it was thought worthwhile to test if the reaction time had any co-relation with learning ability. A comprehensive test was designed to test all the students under study for their ability to comprehend, learn on their own, analyze and solve a given problem. The test was different from the ordinary annual examination these students face and also care was taken that the evaluator's are not prejudiced or influenced by the results of fig 2 . Fig 3 shows how reaction time seem to co-relate strongly with the student's ability to learn. This result is consistent with the findings of Deary et al [14. All these students were admitted to the college based on their performance in higher secondary (HS) examination conductedd by CBSE (India). All the students had marks between $78-84 \%$ in 


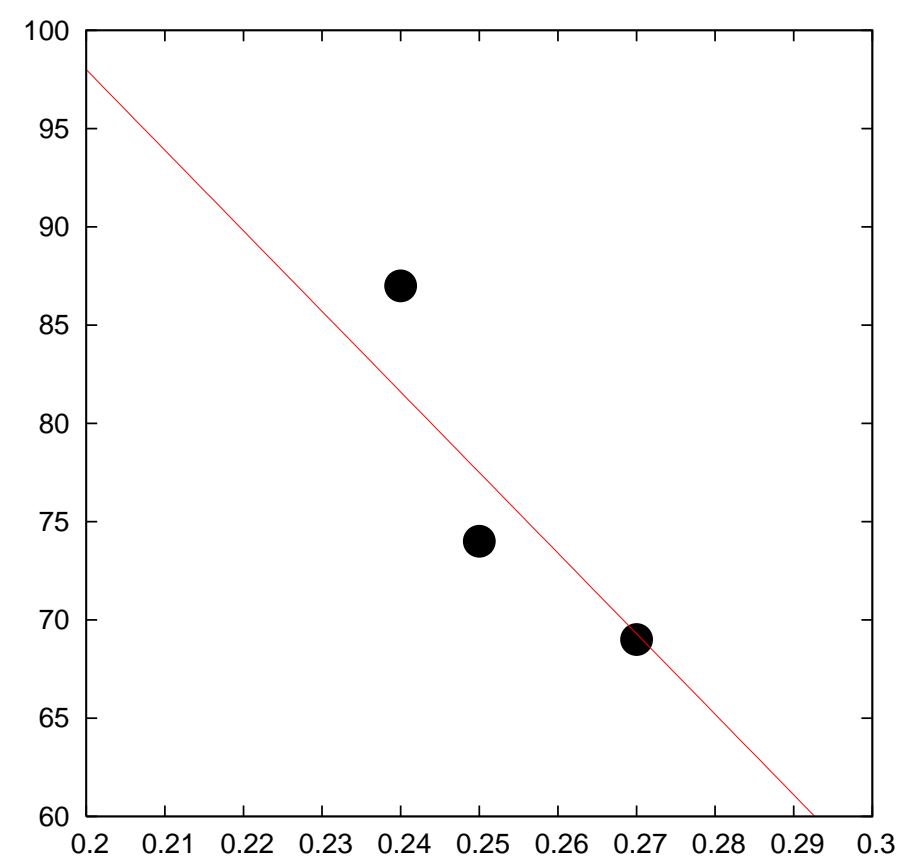

Figure 3: Comparing the performance of the students of $1^{\text {st }}, 2^{\text {nd }}$ and $3^{\text {rd }}$ year in an exam as a function of their class's mean reaction time. The line is only to show trend.

their HS examination. The resolving of their performance with respect to their reaction time hence was made possible because of the complex method adopted for evaluation. Schweitzer [15] in his paper reports that the speed advantage of more intelligent people is greatest in tests requiring complex responses. In corollary, fig 3 suggests sharper (faster) students are stimulated and respond keenly to tests having a degree of complexity.

Another interesting result we have is how the students reaction time varies after they attend an hour of tendious lecture. We took recordings of the first year students before they entered the lecture hall and again, an hour later as they emerged from their Mathematical Physics class. The particular subject was selected after studying their response to a questionaire, where majority reported 


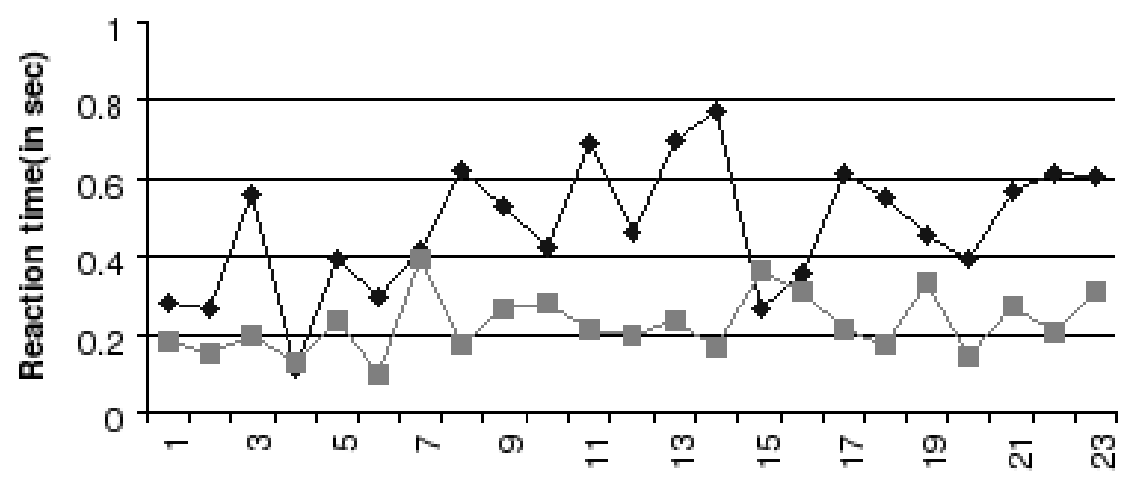

Roll no.

Figure 4: The variation in reaction time after the students went through a "stressful" hour of theory class in Mathematical Physics. Clearly their reflexes were found wanting after the class.

it as the most difficult subject. The subject was also low on popularity. Also, their performance in class tests were consistently poor. Fig 4 shows the variation of performance. Barring four students, all the students showed deterioration in reaction. "Stress", hence, makes the reaction time poor. Slower response due to fatigue doing complicated task was reported as back as in 1953 [16].

\section{Conclusion}

In conclusion, the fatigue level seen in students after attending an hour of intense training in Mathematical Physics does advocate reducing the duration of a lecture from 60 minutes to $40-45$ minutes for students below 21 years. A reduction in response time is also a reduction in concentration level and hence suggests much of the information imparted by the instructor (Fig 4) would have anyway not been absorbed. The methodolgy adopted in teaching difficult subjects also should be reviewed 1 .

\footnotetext{
${ }^{1}$ This statement is reserved for methodolgy followede in Delhi University, since the authors are in no position to comment on senarios elsewhere.
} 
The Gender myth that girls are poor in subjects like maths and engineering subjects were also broken in this sample of study.

\section{References}

[1] http://biae.clemson.edu/bpc/bp/Lab/110/reaction.htm

[2] F. C. Donders, "On the speed of mental processes," Translated by W. G. Koster, Acta Psychologica 30 (1969) 412-431.

[3] P. McLeod, "Visual reaction time and high-speed ball games,", Perception, 16 (1987) 49-59.

[4] F. Galton, "On instruments for (1) testing perception of differences of tint and for (2) determining reaction time.", Journal of the Anthropological Institute, 19 (1899) 27-29.

[5] K. von Fieandt, A. Huhtala, P. Kullberg, and K. Saarl, "Personal tempo and phenomenal time at different age levels", Reports from the Psychological Institute, 2 (1956).

[6] A. T. Welford, "Motor performance. In J. E. Birren and K. W. Schaie (Eds.), Handbook of the Psychology of Aging" Van Nostrand Reinhold, New York (1977) pp. 450-496.

[7] A. T. Welford, "Choice reaction time: Basic concepts." In A. T. Welford (Ed.), Reaction Times. Academic Press, New York (1980), pp. 73-128.

[8] J. T. Brebner, and A. T. Welford, "Introduction: an historical background sketch", In A. T. Welford (Ed.), Reaction Times. Academic Press, New York (1980), pp. 1-23. 
[9] R. D. Luce, "Response Times: Their Role in Inferring Elementary Mental Organization", Oxford University Press, New York (1986).

[10] A. F. Sanders, "Elements of Human Performance: Reaction Processes and Attention in Human Skill". Lawrence Erlbaum Associates, Publishers, Mahwah, New Jersey (1988).

[11] C. J. Bellis, "Reaction time and chronological age.", Proceedings of the Society for Experimental Biology and Medicine 30 (1933) 801.

[12] B. T. Engel, P. R. Thorne, and R. E. Quilter, "On the relationship among sex, age, response mode, cardiac cycle phase, breathing cycle phase, and simple reaction time.", Journal of Gerontology 27, (1972) 456-460.

[13] I. W. Silverman, "Sex differences in simple visual reaction time: a historical meta-analysis (sports events).". Sex Roles: A Journal of Research 54, (2006) $57-69$

[14] I.J. Deary, G. Der and G. Ford, "Reaction times and intelligence differences: A population-based cohort study.", Intelligence 29, (2001) 389.

[15] K. Schweitzer, "Preattentive processing and cognitive ability.", Intelligence 29 (2001) 169.

[16] W. T. Singleton, "Deterioration of performance on a short-term perceptualmotor task.", In W. F. Floyd and A. T. Welford (Eds.), Symposium on Fatigue. H. K. Lewis and Co., London (1953), 163-172. 